\title{
Increased expression of IL-19 in the epithelium of patients with chronic rhinosinusitis and nasal polyps
}

\author{
E. Pace ${ }^{1}$, V. Scafidi ${ }^{1,2}$, D. Di Bona ${ }^{1,2}$, L. Siena $^{1}$, G. Chiappara ${ }^{1}$, M. Ferraro ${ }^{1}$, S. La Grutta ${ }^{3}$, \\ S. Gallina ${ }^{4}$, R. Speciale ${ }^{4}$, A. Ballacchino ${ }^{4}$, C. Bachert ${ }^{5}$, J. Bousquet ${ }^{6}$ \& M. Gjomarkaj ${ }^{1}$ \\ ${ }^{1}$ Institute of Biomedicine and Molecular Immunology (IBIM), National Research Council (CNR); ${ }^{2}$ Dipartimento di Biopatologia e Metodologie \\ Biomediche, Università degli Studi di Palermo; ${ }^{3}$ Environmental Health, ARPA; ${ }^{4}$ Dipartimento di Biomedicina Sperimentale e Neuroscienze \\ Cliniche- Sezione di Otorinolaringoiatria, Università degli Studi di Palermo, Palermo, Italy; ${ }^{5}$ Department of Otorhinolaryngology, Upper Airway \\ Research Laboratory (URL), University Hospital Ghent, Ghent, Belgium; ${ }^{6}$ University Hospital, Montpellier, France
}

To cite this article: Pace E, Scafidi V, Di Bona D, Siena L, Chiappara G, Ferraro M, La Grutta S, Gallina S, Speciale R, Ballacchino A, Bachert C, Bousquet J, Gjomarkaj M, Increased expression of IL-19 in the epithelium of patients with chronic rhinosinusitis and nasal polyps. Allergy 2012; 67: 878-886.

\section{Keywords}

asthma; inflammation; nasal polyps; rhinitis.

\section{Correspondence}

Elisabetta Pace, Istituto di Biomedicina e Immunologia Molecolare -Consiglio

Nazionale delle Ricerche - Via Ugo La

Malfa, 153 - 90146 Palermo, Italy.

Tel.: +390916809148

Fax: +390916809122

E-mail: pace@ibim.cnr.it

Accepted for publication 05 April 2012

DOI:10.1111/j.1398-9995.2012.02842.x

Edited by: Hans-Uwe Simon

\begin{abstract}
Background: Chronic rhinosinusitis (CRS) is an inflammation of the nose and of the paranasal sinuses. The involvement of the respiratory epithelium in the mechanisms of CRS is poorly understood.

Aims: Among proteins expressed by nasal epithelial cells in CRS, IL-19 may have key functions. We here aimed to determine the expression and regulation of IL-19. Methods: Nasal biopsies from normal subjects $(n=12)$, subjects with CRS but without nasal polyps (NP) (CRSsNP, $n=12)$ and with CRS with NP (CRSwNP, $n=15$ ) were collected. Human Asthma Gene Array and real-time PCR were used to evaluate gene expression, western blot analysis and immunohistochemistry for protein expression. Results for IL-19 were confirmed by real-time PCR. The constitutive and stimulated (LPS, TGF $\beta$ ) expression of IL-19 and cell proliferation were evaluated in a nasal epithelial cell line (RPMI 2650).

Results: Human Asthma Gene Array showed an increased IL-19 gene expression in NP from patients with CRS in comparison with normal subjects. Real-time PCR confirmed the IL-19 mRNA up-regulation in patients with CRSwNP and showed an up-regulation of IL-19, at lower extent, in patients with chronic rhinosinusitis without nasal polyps (CRSsNP) in comparison with normal subjects. Western blot analysis confirmed that IL-19 is increased also at protein level in patients with CRSwNP in comparison with normal subjects. In NP, IL-19 is highly expressed in the metaplastic nasal epithelium when compared to normal or hyperplastic epithelium. LPS stimulation increased IL-19 expression, and recombinant IL-19 increased cell proliferation in nasal epithelial cells.

Conclusions: IL-19 is overexpressed in the epithelium in CRSwNP and increases epithelial cell proliferation.
\end{abstract}

Chronic rhinosinusitis (CRS) is an inflammation of the nose and of the paranasal sinuses, which may be differentiated in CRS without (CRSsNP) and with nasal polyps (CRSwNP) based on remodelling and inflammatory patterns $(1,2)$.

\footnotetext{
Abbreviations

CRS chronic rhinosinusitis; CRSwNP chronic rhinosinusitis with nasal polyps; CRSsNP chronic rhinosinusitis without nasal polyps; IL interleukin; NP nasal polyps.
}

CRSwNP is mainly characterized by eosinophilic inflammation and prevalent helper $\mathrm{T}$ cell type(Th)-2 responses while CRSsNP is characterized by neutrophilic inflammation and prevalent Th1 responses (3). The aetiology and pathogenesis of CRS are largely unknown, and abnormalities in host response to external insults including allergens, fungi, bacteria and virus have been suggested to underlie the persistence of the inflammatory state (4). Among these, Staphylococcus aureus may play an important role by releasing enterotoxins, acting as superantigens and amplifying the Th2-biased 
immune response (5). Histological features of CRSwNP resemble that of asthmatic airways with end-stage polyps displaying signs of Th2 inflammation characterized by infiltration with eosinophils, thickening of the basement membrane, and hyperplasia of the epithelium and are strikingly reminiscent of the histopathology of severe asthmatic airways (6). Patients with severe and/or uncontrolled asthma have more severe nasal computed tomographic (CT) scan abnormalities than other patients (7). Multiple mechanisms may contribute to the increase in Th2 responses. In asthmatic patients, IL-17A and IL-4/IL-13 synergistically up-regulate IL-19 expression in airway epithelium, which in turn induces the expression of Th2 cytokines in activated T lymphocytes (8). Nasal epithelium plays a crucial role in innate and adaptative immune responses, and alterations in epithelial barrier function and host defence responses may contribute to CRS pathogenesis $(9,10)$. The immune mechanisms promoting the structural alterations in CRS are not well elucidated.

In the present study, based on a gene array, we focus on IL-19 RNA and protein expression and regulation of its production as a possible key cytokine in the regulation of $\mathrm{Th} 2$ responses in CRS with NP.

\section{Materials and methods}

\section{Study population}

Patients were recruited at the ENT departments of Palermo, Italy, and of Ghent, Belgium. We selected subjects without CRS $(n=12)$ (age, 18-48 year) and without allergic diseases or asthma (controls), subjects with CRS but without NP (CRSsNP) $(n=12)$ (age, 23-51 year) and subjects with CRS and NP (CRSwNP) ( $n=15)$ (age, 20-48 year) (11). The study fulfilled the criteria of the Ethics Committee of both hospitals and was in agreement with the Helsinki Declaration. All subjects had given their written informed consent. Further details are provided in the Supporting information.

\section{Nasal biopsies}

Nasal biopsies were collected from inferior turbinates or from nasal polyps. For mRNA analyses, nasal biopsies were immediately kept in RNA-latter and snap-frozen at $-80^{\circ} \mathrm{C}$. For immunohistochemistry, nasal biopsies were fixed $(10 \%$ neutral buffer formalin) and embedded in paraffin wax. Some nasal biopsies from CRSwNP were freshly processed to isolate nasal epithelial cells as previously described (12).

\section{cDNA expression array}

Total RNA was isolated from the samples using TriZol reagent (Invitrogen, Carlsbad, CA, USA) (13), and RNA purification was performed with RNeasy Mini kit (Qiagen Inc, Valencia, CA, USA). Human Asthma Gene Array, analysing 85 asthma related genes simultaneously (SuperArray Inc., Bethesda, MD, USA), was used to compare the gene expression profiles of the collected samples as previously described (14). The averages of two GAPDH or four cyclophilin A spots were used as positive controls and set as baseline values with which the signal intensity of other spots was compared. Using these normalized data, we compared the signal intensity from the membranes using the GEarray analyzer program (SuperArray Corp., http://www.superarray.com).

\section{Real-time quantitative RT-PCR of IL-19}

Real-time quantitative PCR of IL-19 transcript was carried out on ABI PRISM 7900 HT Sequence Detection Systems (Applied Biosystems, Foster City, CA, USA) using specific FAM-labelled probe and primers (Assays on Demand; Applied Biosystems). Relative quantitation of mRNA levels was carried out with comparative $C_{T}$ method $\left(2^{-\Delta \Delta C t}\right)$ (15).

\section{Western blot analysis}

The expression of IL-19 was evaluated by western blot analysis as previously described (16) using a goat polyclonal antibody anti-IL-19 (1 : 100) (Santa Cruz Biotechnology, Santa Cruz, CA, USA). Membranes were then stripped and incubated with goat polyclonal anti-ß-actin (Sigma-Aldrich, St Louis, MO, USA). Revelation was performed with an enhanced chemiluminescence system (GE Healthcare, Chalfont St. Giles, UK) followed by autoradiography. Negative controls were performed without primary antibody or including an isotype control antibody. Data are expressed as densitometric arbitrary units by correction with the density of the bands obtained for beta-actin.

\section{Immunohistochemistry}

Immunohistochemistry was performed using goat anti-human IL-19 polyclonal antibody (Santa Cruz Biotechnology) (1: 50) or using mouse anti-human Ki67 monoclonal antibody (Clone MIB-1; Code n. M7240; Dako, Glostrup, Denmark) (1:75). For IL-19 expression, the intensity and percentage scores were multiplied to give a composite score of 1-9 for each specimen as previously described (17) (further details in the Supporting information). For the Ki67 expression, the percentage of Ki67-positive cells was assessed in normal/hyperplastic and in metaplastic epithelium of nasal polyps from CRSwNP subjects.

\section{Immunofluorescence microscopy}

Immunofluorescence staining was performed on tissue sections from CRSwNP subjects to evaluate the co-localization of IL-19 and Ki67. Immunostainings were performed using goat anti-human IL-19 polyclonal antibody (Santa Cruz Biotechnology) (1:50) and mouse anti-human monoclonal ki67 antibody (Clone MIB-1; Code n. M7240; Dako) ( $1: 75)$. Double labelling was performed using a secondary fluorescein isothiocyanate-conjugated donkey anti-goat antibody and phycoerythrin (PE)-conjugated goat anti-mouse antibody (Sigma-Aldrich) in the same section. Slides were analysed by a fluorescence microscope (Axioscop 2; Zeiss, Heidelberg, Germany) at 488 lambda for the green fluorescence and at 589-610 lambda for the red fluorescence. 


\section{Nasal epithelial cell line}

RPMI 2650, a nasal epithelial cell line was cultured with endotoxin (LPS 1 and $10 \mu \mathrm{g} / \mathrm{ml}-24 \mathrm{~h}$ ) (Sigma-Aldrich) for assessing IL-19 expression and with recombinant IL-19 ( $\mathrm{r}$ IL-19) (200 ng/ml) (R\&D Systems, Minneapolis, MN, USA), herbimycin, a tyrosine kinase inhibitor (Sigma) $(2 \mu \mathrm{M})$ and $\mathrm{Na}$ orthovanadate, a tyrosine phosphatase inhibitor (Sigma) $(10 \mu \mathrm{M})(15)$, for $72 \mathrm{~h}$ for assessing cell proliferation as previously described (18). The time point was selected on the basis of preliminary experiments (data not shown). At the end of stimulation, cells were collected for assessing IL-19 expression and/or for cell proliferation.

Expression of IL-19 and of ki67 in nasal epithelial cells

The IL-19 protein expression was assessed by western blot (as mentioned previously) and by flow cytometry analysis. The ki67 was assessed by flow cytometry analysis. RPMI 2650 cells and primary epithelial cells isolated from a CRSwNP were used for these experiments. The expression of IL-19 and of ki67 by flow cytometry was assessed in permeabilized cells. Data are expressed as percentage of positive cells.

\section{Cell proliferation}

RPMI 2650 was stimulated with r IL-19 with/without herbimycin and $\mathrm{Na}$ orthovanadate. Cell proliferation was assessed using carboxyfluorescein succinimidyl ester (19) labelling assay and by clonogenic assay (15). Further details are provided in the Supporting information.

\section{Statistics}

Data are expressed as median (25-75 percentiles). KruskalWallis test was performed for comparisons between patient groups. A nonparametric Mann-Whitney test was applied as the initial Kruskal-Wallis test was significant. The Spearman test was used for correlations. Student's paired t-test was used for comparisons in RPMI cell line. $P<0.05$ was accepted as statistically significant.

\section{Results}

\section{Demographic characteristics of the subjects}

The demographic characteristics and the clinical evaluations of the studied patients are shown in Table 1 .

Table 1 Demographic characteristics of the subjects

\begin{tabular}{lccc}
\hline & Controls $=12$ & CRSsNP $=12$ & CRSw NP $=15$ \\
\hline Gender (M/F) & $5 / 7$ & $7 / 5$ & $7 / 8$ \\
Asthma & $0 / 12$ & $4 / 12$ & $8 / 15$ \\
Atopy & $0 / 12$ & $5 / 12$ & $7 / 15$ \\
\hline
\end{tabular}

CRSsNP, chronic rhinosinusitis without nasal polyps.
Increased expression of IL-19 mRNA in CRS with nasal polyps by Human Asthma Gene Array

Human Asthma Gene Array, analysing 85 asthma related genes simultaneously (Table S1 in the Supporting information), showed an greater than fivefold increase in IL-19 in CRSwNP in comparison with controls (Fig. 1A). No significant differences were observed between CRSsNP and normal controls (Fig. 1B,C).

\section{Real-time PCR confirms the increased expression of IL-19 mRNA in CRS with nasal polyps}

Real-time PCR confirmed that IL-19 mRNA was strongly up-regulated in patients with CRSwNP and showed a significant up-regulation of IL-19 mRNA, at lower extent, also in the mucosa from inferior turbinate of patients with CRSsNP in comparison with controls (Fig. 1D).

\section{Increased expression of IL-19 protein in CRS with nasal polyps.}

Western blot analysis confirmed that IL-19 is increased also at protein level in patients with CRSwNP in comparison with controls (Fig. 2A,B). There was no significant trend in the increase in IL-19 protein in CRSsNP.

\section{Squamous metaplastic nasal epithelium shows higher} expression of IL-19 protein in CRS with nasal polyps

Immunohistochemistry, applied to identify which cells express IL-19, showed that IL-19 is highly expressed in the epithelium of CRSsNP and of CRSwNP in comparison with controls (Fig. 3A). In the subepithelial compartment, mucous glands mainly expressed IL-19. In CRSwNP, higher expression of IL-19 was observed in squamous metaplastic nasal epithelium (score, 4-9) when compared to not metaplastic nasal epithelium (normal or hyperplastic epithelium) (score, 1 -3) (Fig. 3B). Confirming what previously was reported (10), basal hyperplasia and mucous cell hyperplasia were observed in CRSwNP (see arrow and arrowhead in Fig. 3B). In patients with CRSwNP, IL-19 expression was independent of atopy as defined by a positive SPT (data not shown) or of asthma.

\section{Nasal epithelial cells constitutively express IL-19}

The expression of IL-19 in nasal epithelium may be the result of a paracrine or an autocrine mechanism. Nasal epithelial cells constitutively express IL-19, suggesting that the presence of IL-19 in the epithelium of the recruited subjects may represent also the effect of an autocrine production (Fig. 4). LPS ( 1 and $10 \mu \mathrm{g} / \mathrm{ml})$ increased the percentage of IL-19-positive cells (Fig. 4A) and the constitutive production of IL-19 (Fig. 4B) in nasal epithelial cells.

We next explored whether r IL-19 was able to alter cell proliferation in nasal epithelial cells and whether cell proliferation was affected by herbimycin and by $\mathrm{Na}$ orthovanadate, 
A

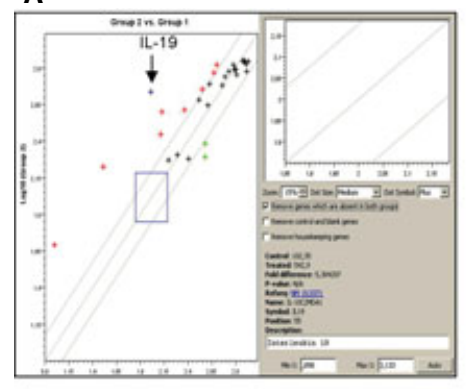

B

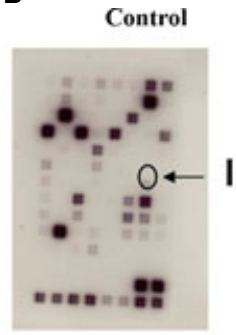

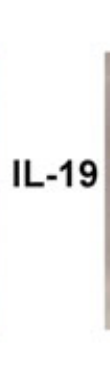

CRSsNP

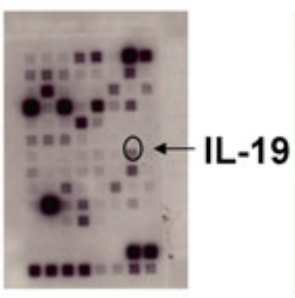

CRSwNP

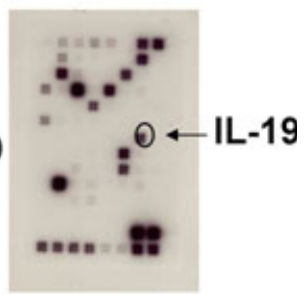

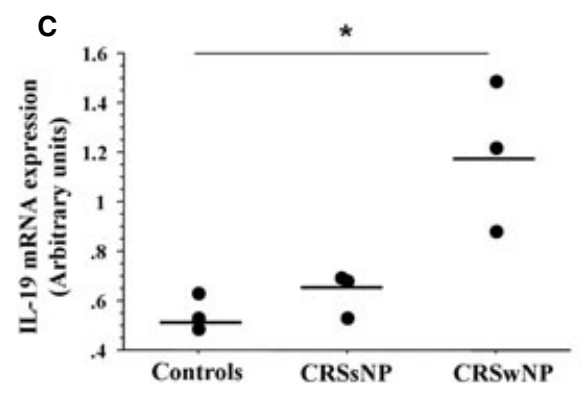

Figure 1 Increased expression of IL-19 mRNA in chronic rhinosinusitis (CRS) with nasal polyps by Human Asthma Gene Array. Nasal biopsies were collected from controls $(n=3)$, from subjects with chronic rhinosinusitis without nasal polyps (CRSsNP) $(n=3)$ and from chronic rhinosinusitis with nasal polyps (CRSwNP) $(n=3)$. Total RNA was extracted, and Human Asthma Gene Array was used to compare the gene expression profiles of the collected samples. (A) Representative analysis performed by the GEarray analyzer program showing the differences in gene expression of a control (group 1) and of a CRSwNP (group 2). (B) Representative

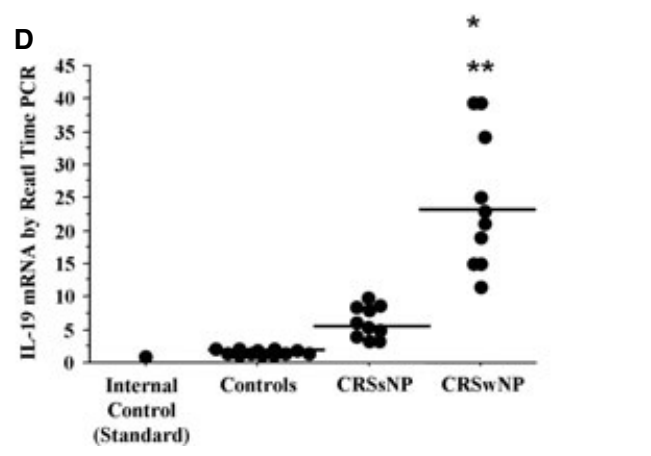

membranes from control, CRS and CRSwNP patients. (C) Densitometric analyses of multiple GEarray experiments $(n=3)$. $* P<0.05$. Individual values are shown. Horizontal bars represent median values. (D) IL-19 m-RNA expression was also assessed by real-time PCR in controls $(n=12), \operatorname{CRSsNP}(n=10)$ and CRSwNP $(n=10)$. GAPDH gene expression was used as endogenous control for normalization. Relative quantitation of mRNA was carried out with comparative CT method. Individual values are shown. Horizontal bars represent median values. * $P<0.002$ vs controls; ** $P<0.002$ vs CRS.

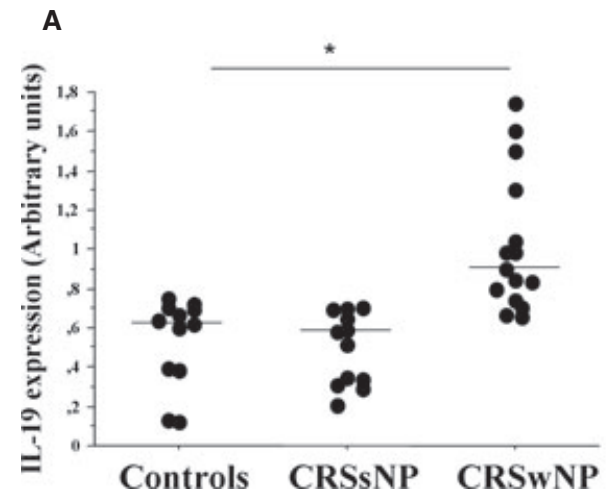

B Control CRSsNP CRSwNP

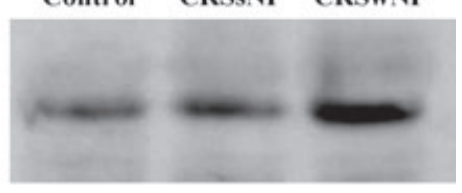

\section{Interleukin-19}

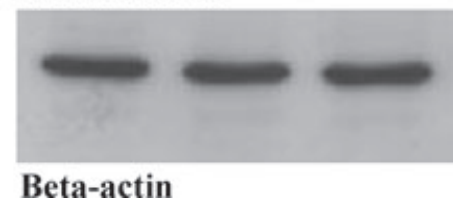

Figure 2 Increased expression of IL-19 protein in chronic rhinosinusitis (CRS) with nasal polyps by western blot analysis. Nasal biopsies were collected from controls $(n=12)$, from CRSsNP $(n=12)$ and from CRSwNP $(n=15)$. Total proteins were extracted and analysed for IL-19 expression by western blot analysis. Membranes were then stripped and incubated with goat polyclonal anti-ß-actin. (A) Densitometric analysis of
IL-19 expression. Signals corresponding to IL-19 on the various western blots were semiquantified by densitometric scanning, normalized and expressed after correction with the density of the band obtained for $\beta$-actin. Individual values are shown. Horizontal bars represent median values. ${ }^{*} P<0.05$. (B) Representative western blot analysis for IL-19 expression from a control, a CRS and a CRSwNP. 


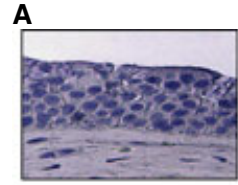

Negative Control
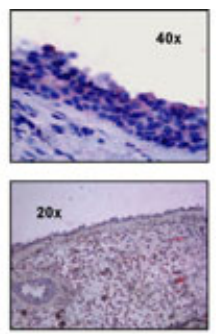

Control
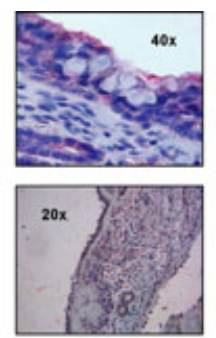

CRSsNP
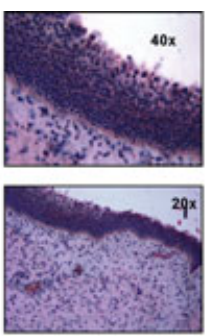

CRSwNP

B

\begin{tabular}{|l|l|l|}
\hline Staining area & Metaplastic Epithelium & $\begin{array}{l}\text { Not Meplastic } \\
\text { Epithelium }\end{array}$ \\
\hline Number of CRSwNP & 15 & 15 \\
\hline Score 1-3 & $3 / 15$ & $13 / 15$ \\
\hline Score 4-9 & $12 / 15$ & $2 / 15$ \\
\hline & & \\
& &
\end{tabular}

Figure 3 Higher expression of IL-19 protein in nasal epithelium of chronic rhinosinusitis (CRS) with nasal polyps. IL-19 expression was assessed by immunohistochemistry in controls $(n=12)$, CRSsNP $(n=12)$ and CRSwNP $(n=15)$. Negative controls were performed using rabbit immunoglobulins negative control. (A) Representative negative control and representative immunostaining (red stain) in a control, a CRSsNP and a CRSwNP at 200x

an inhibitor and an activator of tyrosine kinases, respectively. Recombinant IL-19 alone and with $\mathrm{Na}$ orthovanadate increased while herbimycin reduced the IL19-induced cell proliferation (Fig. 4C,D).

\section{Squamous metaplastic nasal epithelium shows higher expression of Ki67 protein in CRS with nasal polyps}

We finally investigated whether in the squamous metaplastic epithelium, a deregulated expression of Ki67, a marker well correlated with altered cell proliferation (20), occurred. The percentage of Ki67-positive cells was significantly higher in the metaplastic epithelium than in normal epithelium of nasal polyps from CRSwNP (Fig. 5A). Flow cytometry (Fig. 5B) in primary nasal epithelial cells from CRSwNP and immunofluorescence in CRSwNP samples (Fig. 5C-E) showed that Ki67 co-localized with IL-19 in nasal polyps.

\section{Discussion}

This study provides compelling evidence on the role of IL-19 in patients with CRSwNP. We have demonstrated that IL-19 induces nasal cell proliferation, is up-regulated at both mRNA and protein levels and is highly expressed by the and at $400 \times$ magnification. (B) The expression of IL-19 was assessed in metaplastic and in not metaplastic (normal and hyperplastic) epithelium of CRSWNP ( $n=15)$. A composite score was used to evaluate IL-19 expression. At the bottom of the table, representative immunostainings are shown. Arrow points to mucous cell hyperplasia while arrowhead points to basal cell hyperplasia.

squamous metaplastic epithelium of nasal polyps where an increased expression of Ki67 occurs.

CRS is an inflammatory disease with distinct cytokine and remodelling patterns. CRSwNP is characterized by a Th2skewed eosinophilic inflammation, whereas CRSsNP represents a predominant Th1 milieu. CRS severely affects patients' quality of life and complicates inflammation in adjacent organs and worsens associated diseases including asthma (21). On the basis of the 'one-airway hypothesis', we initially approached this study using an Asthma Gene Array to explore the presence, in nasal compartment, of asthma like gene expression alterations. Asthma gene Array demonstrated that IL-19 is up-regulated, and real-time PCR analysis confirmed that IL-19 gene expression was increased in CRSwNP in comparison with normal subjects. Furthermore, IL-19 protein expression was increased in the epithelium of CRSwNP in comparison with normal subjects.

The genes encoding IL-19 and IL-20 cluster into the genomic IL-10 region on human chromosome 1 (22). Microarray technology and an immunohistochemical survey with an antiIL-19 antibody to examine the expression of IL-19 in healthy and neoplastic tissues demonstrated that IL-19 protein was positively stained in healthy lung tissue by epithelial cells, endothelial cells and macrophages (23). 


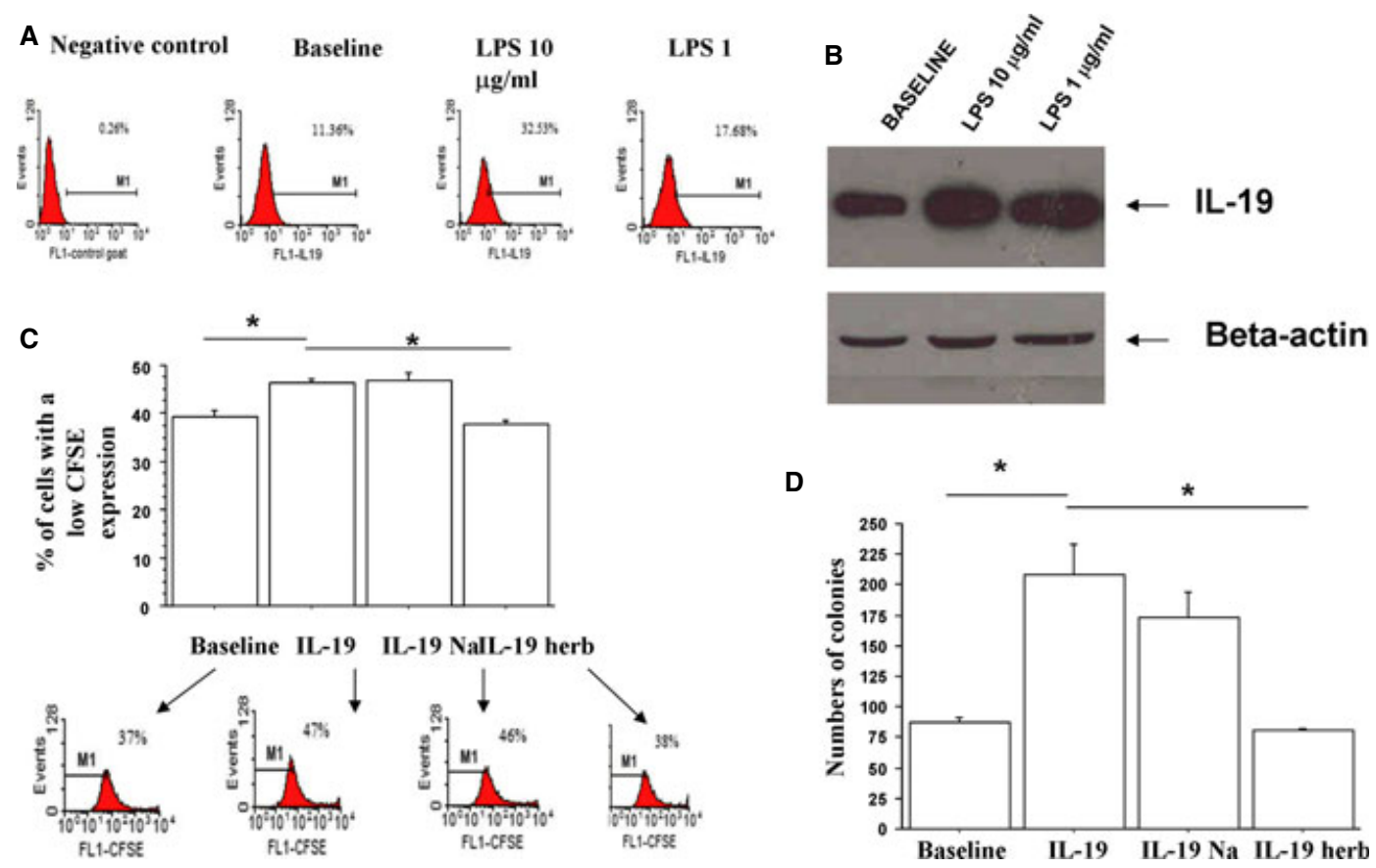

Figure 4 IL-19 expression and cell proliferation in nasal epithelial cells. Flow cytometric analysis (A) and western blot analysis (B) were used for assessing IL-19 expression in a nasal epithelial cell line (RPMI 2650) without or with LPS ( 1 and $10 \mu \mathrm{g} / \mathrm{ml})$ stimulation. (A) Representative histograms of a flow cytometric analysis showing on the left the negative control using goat immunoglobulins negative control, and on the right, the expression of IL-19 in the absence and in the presence of stimuli. (B) Total proteins were extracted and analysed for IL-19 expression by western blot analysis. Membranes were then stripped and

There are limited comprehensive surveys of IL-19 expression in nasal human tissue or nasal cell types, and only few biological functions and clinical implications of IL-19 are known. It has been previously demonstrated that IL-19 down-regulates IL-4-induced eotaxin production in human nasal fibroblasts from patients with allergic rhinitis, (24) but no study specifically investigates the role of IL-19 in nasal epithelium and in CRSwNP.

The synthesis of IL-19 is a tightly regulated mechanism. In the present study, for the first time, a relevant increased expression of IL-19 in nasal epithelial cells was observed after LPS stimulation. In this regard, it has been demonstrated that TLR4 signalling pathway, after LPS stimulation, activates MyD88 and in turn induces Il-19 expression in monocyte cultures $(25,26)$. Moreover, it has recently been demonstrated that nasal epithelial cells stimulated with enterotoxins B from Staphylococcus aureus release chemokines including IL-8 and IP-10 (27) (Huvenne Allergy 2010). Future studies are needed to clarify whether enterotoxins B from S. aureus or Th2 cytokines (IL-4, IL-13) are able to induce IL-19 expression/release. The increased levels of IL19 in CRSwNP may actively contribute to amplify the inflammatory responses in these patients. IL-19, produced incubated with goat polyclonal anti-ß-actin. Representative western blot analysis is shown. Nasal epithelial cell line (RPMI 2650) was cultured with or without $r$ IL-19 $(200 \mathrm{ng} / \mathrm{ml})$ and with IL-19 and herbimycin and $\mathrm{Na}$ orthovanadate. Cell proliferation was assessed using carboxyfluorescein succinimidyl ester (CFSE) by means of flow cytometry (C) and by clonogenic assay (D) (see Materials and Methods for details). (A) Means \pm SD of $n=3$ experiments. $* P<0.05$ paired $t$-test. At the bottom of the panel $A$, one representative experiment is shown. (B) Means $\pm S D$ of $n=3$ experiments. ${ }^{*} P<0.05$ paired $t$-test.

by synovial cells, promotes joint inflammation in rheumatoid arthritis by inducing IL-6 production and decreasing synovial cell apoptosis (28). IL-6 activates Th17 cells and regulates the response of $\mathrm{B}$ lymphocytes and of regulatory $\mathrm{T}$ cells. Consistently, in CRSwNP compared with controls, IL-6 and IL-6 receptor (29) are increased while Foxp3 mRNA, a transcription factor, typically associated with $\mathrm{T}$ regulatory activities was reduced $(30,31)$. Furthermore, the increased release of IL-19 may alter the balance of Th1 and Th2 cells in favour of Th2 cells because this cytokine upregulates IL-4 and down-regulates interferon-c (32,33). In bronchial asthma, a disease associated with increased Th2 responses, IL-19 levels are elevated three- to fourfold (33). High IL-19 levels correlate with high IL-4 and IL-13 levels, and epithelial cells in the airway of human asthma and patients with chronic obstructive pulmonary disease are rich in IL-19 (34). Accordingly, in CRSwNP, IL-5, IL-13 and GATA-3, typically associated with $\mathrm{Th} 2$ responses, are increased (35), and here, we demonstrated that in these patients also IL-19 expression is increased. A positive feedback between the Th2 and IL-19 in asthma has been demonstrated because bronchial epithelial cells stimulated by IL-17 and IL-13 express IL-19 at high levels (34). The 


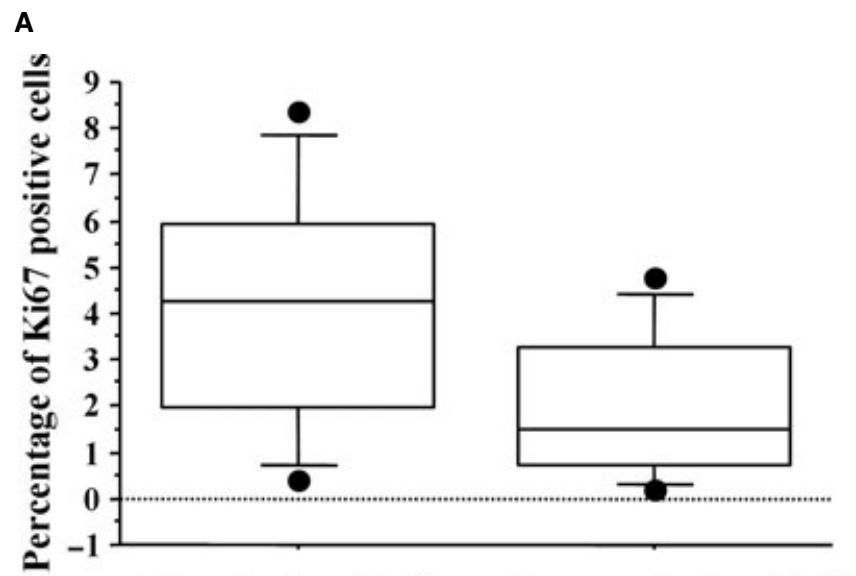

Metaplastic epithelium Not metaplastic epithelium
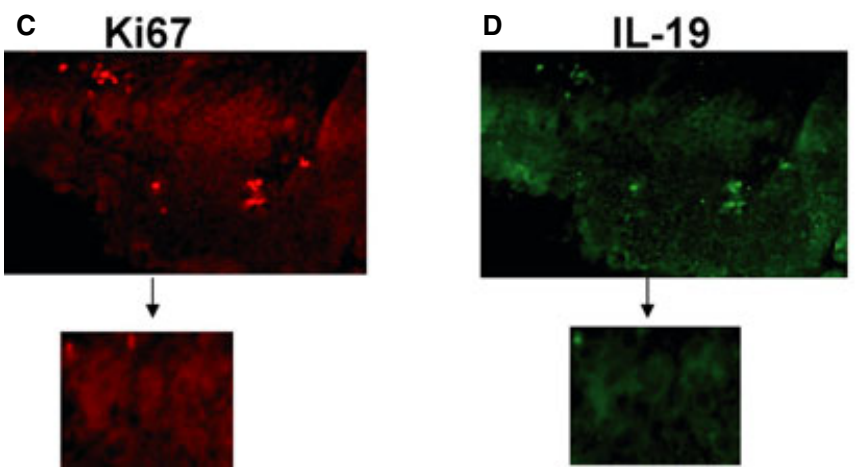
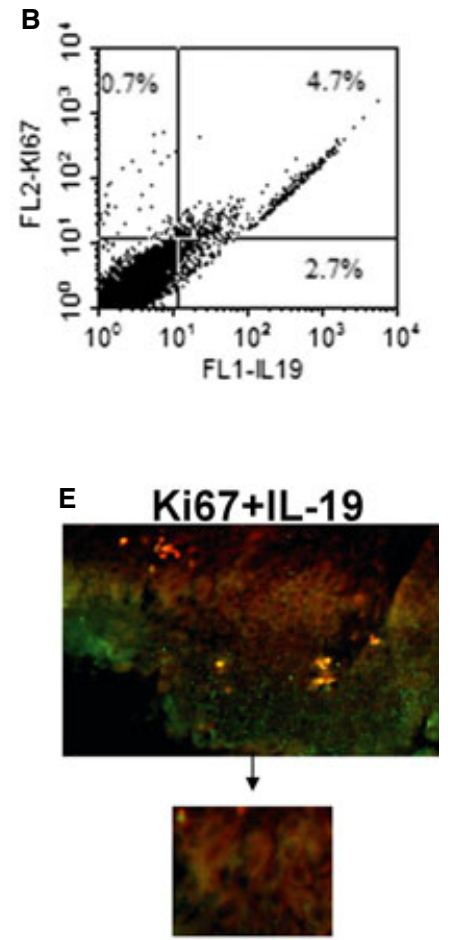

Figure 5 Squamous metaplastic nasal epithelium showed higher expression of Ki67 protein in chronic rhinosinusitis (CRS) with nasal polyps. (A) Immunohistochemistry was performed for assessing Ki67 expression in nasal biopsies collected from CRSwNP patients $(n=15)$. (B) Flow cytometry was performed for assessing the expression of Ki67 and IL-19 on nasal epithelial cells isolated from CRSwNP. A representative experiment is shown. (C-E) Immunofluorescence was performed for assessing

presence of a similar mechanism also in patients with CRSwNP may be supposed.

In addition, the increased levels of IL-19 may alter the proliferation and the differentiation of the nasal epithelium in CRSwNP. In psoriatic skin, IL-19 induces a gene expression profile consistent with inflammatory responses, wound healing re-epithelialization and altered epithelial differentiation (36). Epithelial damage and aberrant tissue remodelling are common features of CRSwNP. Features of nasal remodelling may be considered: squamous metaplasia, basement membrane thickening, collagen deposition, hyperplasia of mucous glands and goblet cells (37). Here, squamous metaplastic nasal epithelium showed higher expression of IL-19 protein. Nasal epithelial cells from patients with nasal polyps demonstrated faster growth rates, and VEGF regulates nasal epithelial cell proliferation because exposure of cells to blocking antibodies against VEGF resulted in the inhibition of cell growth (38). IL-19 specifically activated an intracellular signal and induced proliferation in oral cancer cells (23). The
Ki67 (red fluorescence) and IL-19 (green fluorescence) expression in nasal biopsies collected from patients with CRS and NP (CRSwNP) $(n=3)$. A representative experiment is shown. (C) Single immunofluorescence for Ki67. (D) Single immunofluorescence for IL-19. (E) Merged immunofluorescence for IL-19 and Ki67. For single ki67 and IL-19 and for double ki67/IL-19, a particular from a higher magnification is shown. See Materials and Methods for details.

binding of IL-19 to its receptor complex activates, as main pathways, the tyrosine phosphorylation and the signal transducers and activators of transcription (STAT) pathways, notably STAT1 and STAT3 $(26,39,40)$. In the present study, IL-19 increased nasal epithelial cell proliferation, and herbimycin, a tyrosine kinase inhibitor, reduced IL-19-induced nasal epithelial cell proliferation, suggesting that the proliferative role of IL-19 in nasal epithelial cells is mediated by tyrosine phosphorylation events. Furthermore, IL-19 maximally activates tyrosine phosphorylation because the presence of $\mathrm{Na}$ orthovanadate, a phosphotyrosine phosphatases inhibitor, did not further increase cell proliferation. Finally, squamous metaplastic nasal epithelium and primary nasal epithelial cells from patients with CRSwNP highly coexpressed IL-19 and Ki67. Ki67 is vital for cell proliferation, and patients with CRSwNP and higher Ki67 planoepithelial metaplasia are the subgroup with eosinophilic infiltrations (41). Additional studies are needed to clarify the role of IL19 in the Th2 bias and development of nasal polyps. 


\section{Acknowledgments}

This work was supported by the Italian National Research Council and by EU Framework programme for research, contract no FOOD-CT-2004-506378, the GA2LEN project, Global Allergy. Elisabetta Pace designed the study, performed the statistical analysis of the data, and wrote the manuscript and declares that she has had access to and takes responsibility for the integrity of the data and the accuracy of the data analysis.Valeria Scafidi, Danilo Di Bona, Liboria Siena, Giuseppina Chiappara and Maria Ferraro performed all the experiments of the study and participated in the interpretation of the data. Stefania La Grutta, Salvatore Gallina, Riccardo Speciale and Antonella Ballacchino contributed to the patient selection, collected and managed biological samples. Jean Bousquet, Claus Bachert and Mark Gjomarkaj contributed to the interpretation of the data and to the writing out of the manuscript.

\section{Conflicts of interest}

Jean Bousquet has received honoraria for scientific and advisory boards, lectures during meetings, press conferences from Stallergènes, Actelion, Almirall, AstraZeneca, Chiesi, GSK, Merck, MSD and Novartis and all other authors declares no competing interests.

\section{Supporting Information}

Additional Supporting Information may be found in the online version of this article:

Data S1. Methods.

Table S1. List of 85 genes present in Asthma Gene Array.

Please note: Wiley-Blackwell are not responsible for the content or functionality of any supporting materials supplied by the authors. Any queries (other than missing material) should be directed to the corresponding author for the article.

\section{References}

1. Van Bruaene N, Derycke L, Perez-Novo CA, Gevaert P, Holtappels G, De Ruyck N et al.TGF-beta signaling and collagen deposition in chronic rhinosinusitis. $J$ Allergy Clin Immunol 2009;124:253-259.

2. Van Zele T, Claeys S, Gevaert P, Holtappels G, Van Cauwenberge P, Bachert C. Differentiation of chronic sinus diseases by measurement of inflammatory mediators. Allergy 2006;61:1280-1289.

3. Bachert C, Van Bruaene N, Toskala E, Zhang N, Olze H, Scadding G et al.Important research questions in allergy and related diseases: 3-chronic rhinosinusitis and nasal polyposis - a GALEN study. Allergy 2009;64:520-533.

4. Kern RC, Conley DB, Walsh W, Chandra R, Kato A, Peters AT et al. Perspectives on the etiology of chronic rhinosinusitis: an immune barrier hypothesis. Am J Rhinol 2008;22:549-559.

5. Bachert C, Gevaert P, Zhang N, van Zele T, Perez-Novo C. Role of staphylococcal superantigens in airway disease. Chem Immunol Allergy 2007;93:214-236.

6. Bachert C, Patou J, Van Cauwenberge P. The role of sinus disease in asthma. Curr Opin Allergy Clin Immunol 2006;6:29-36.

7. Bousquet J, Bachert C, Canonica GW, Casale TB, Cruz AA, Lockey RJ, Zuberbier T, Extended Global Allergy and Asthma European Network, World Allergy Organization and Allergic Rhinitis and its Impact on Asthma Study Group. Unmet needs in severe chronic upper airway disease (SCUAD). J Allergy Clin Immunol 2009;124:428-433.

8. Huang F, Wachi S, Thai P, Loukoianov A, Tan KH, Forteza RM, Wu R. Potentiation of IL-19 expression in airway epithelia by IL-17A and IL-4/IL-13: important implica- tions in asthma. J Allergy Clin Immunol 2008;121:1415-1421.

9. Tieu DD, Kern RC, Schleimer RP. Alterations in epithelial barrier function and host defense responses in chronic rhinosinusitis. J Allergy Clin Immunol 2009;124:37-42.

10. Bernstein JM. The molecular biology of nasal polyposis. Curr Allergy Asthma Rep 2001;1:262-267.

11. Fokkens W, Lund V, Bachert C, Clement P, Helllings $\mathrm{P}$, Holmstrom $\mathrm{M}$ et al. EAACI position paper on rhinosinusitis and nasal polyps executive summary. Allergy 2005;60:583-601.

12. Wiesel JM, Gamiel H, Vlodavsky I, Gay I, Ben-Bassat H. Cell attachment, growth characteristics and surface morphology of human upper-respiratory tract epithelium cultured on extracellular matrix. Eur J Clin Invest 1983;13:57-63.

13. Chomczynski P, Sacchi N. The single-step method of RNA isolation by acid guanidinium thiocyanate-phenol-chloroform extraction: twenty-something years on. Nat Protoc 2006;1:581-585.

14. Bolger WE, Joshi AS, Spear S, Nelson M, Govindaraj K. Gene expression analysis in sinonasal polyposis before and after oral corticosteroids: a preliminary investigation. Otolaryngol Head Neck Surg 2007;137:2733.

15. Pace E, Siena L, Ferraro M, Profita M, Mondello P, Chiappara G, Montalbano AM, Giarratano A, Bonsignore G, Gjomarkaj M. Role of prostaglandin E2 in the invasiveness, growth and protection of cancer cells in malignant pleuritis. Eur J Cancer 2006;42:2382-2389.

16. Pace E, Ferraro M, Uasuf CG, La Grutta S, Liotta G, Giarratano A, Johnson M, Gjomarkaj M. Cilomilast counteracts the effects of cigarette smoke in innate responses of airway epithelial cells. Cell Immunol 2011;268:47-53.

17. Ko YH, Roh SY, Won HS, Jeon EK, Hong SH, Lee MA, Kang JH, Hong YS, Kim MS, Jung CK. Prognostic significance of nuclear survivin expression in resected adenoid cystic carcinoma of the head and neck. Head Neck Oncol 2010;2:30.

18. Pace E, Ferraro M, Mody CH, Melis M, Bonanno A, Profita M, Giarratano A, Gjomarkaj M. Pleural mesothelial cells express both BLT2 and PPARa and mount an integrated response to pleural $\mathrm{LTB}_{4}$. J Immunol 2008;181:7292-7299.

19. Pochard P, Vickery B, Berin MC, Grishin A, Sampson HA, Caplan M, Bottomly K. Targeting Toll-like receptors on dendritic cells modifies the $\mathrm{T}(\mathrm{H}) 2$ response to peanut allergens in vitro. $J$ Allergy Clin Immunol 2010;126:92-97.

20. Bolton SJ, Pinnion K, Oreffo V, Foster M, Pinkerton KE. Characterisation of the proximal airway squamous metaplasia induced by chronic tobacco smoke exposure in spontaneously hypertensive rats. Respir Res 2009;10:118.

21. Jarvis D, Newson R, Lotvall J, Hastan D, Tomassen P, Keil T, Gjomarkaj M, Forsberg B, Gunnbjornsdottir M, Minov J, Brozek G, Dahlen SE, Toskala E, Kowalski ML, Olze H, Howarth P, Krämer U, Baelum J, Loureiro C, Kasper L, Bousquet PJ, Bousquet J, Bachert C, Fokkens W, Burney P. Asthma in adults and its association with chronic rhinosinusitis: the $\mathrm{GA}^{2} \mathrm{LEN}$ survey in Europe. Allergy 2012;67:91-98.

22. Fickenscher H, Hör S, Küpers H, Knappe A, Wittman S, Sticht H. The interleukin-10 family of cytokines. Trends Immunol 2002;23:89-96. 
23. Hsing $\mathrm{CH}$, Li HH, Hsu YH, Ho CL, Chuang SS, Lan KM, Chang MS. The distribution of interleukin-19 in healthy and neoplastic tissue. Cytokine 2008;44:221.

24. Higashino M, Takabayashi T, Takahashi N, Okamoto M, Narita N, Kojima A, Hyo S, Kawata R, Takenaka H, Fujieda S. Interleukin-19 downregulates interleukin-4-induced eotaxin production in human nasal fibroblasts. Allergol Int 2011;60:449-457.

25. Conti P, Kempuraj D, Frydas S, Kandere K, Boucher W, Letourneau R, Madhappan B, Sagimoto K, Christodoulou S, Theoharides TC. IL-10 subfamily members: IL-19, IL-20, IL-22, IL-24 and IL-26. Immunol Lett 2003;88:171-174.

26. Azuma YT, Matsuo Y, Nakajima H, Yancopoulos GD, Valenzuela DM, Murphy AJ, Karow M, Takeuchi T. Interleukin-19 is a negative regulator of innate immunity and critical for colonic protection. J Pharmacol Sci 2011;115:105-111.

27. Huvenne W, Callebaut I, Reekmans K, Hens G, Bobic S, Jorissen M, Bullens DM, Ceuppens JL, Bachert C, Hellings PW. Staphylococcus aureus enterotoxin B augments granulocyte migration and survival via airway epithelial cell activation. Allergy 2010;65:1013-1020.

28. Sakurai N, Kuroiwa T, Ikeuchi H, Hiramatsu N, Maeshima A, Kaneko Y, Hiromura K, Nojima Y. Expression of IL-19 and its receptors in RA: potential role for synovial hyperplasia formation. Rheumatology (Oxford) 2008;47:815-820.

29. Peters AT, Kato A, Zhang N, Conley DB, Suh L, Tancowny B, Carter D, Carr T, Rad- tke M, Hulse KE, Seshadri S, Chandra R, Grammer LC, Harris KE, Kern R, Schleimer RP. Evidence for altered activity of the IL-6 pathway in chronic rhinosinusitis with nasal polyps. $J$ Allergy Clin Immunol 2010; 125:397-403.

30. Van Bruaene N, Pérez-Novo CA, Basinski TM, Van Zele T, Holtappels G, De Ruyck N, Schmidt-Weber C, Akdis C, Van Cauwenberge P, Bachert C, Gevaert P. T-cell regulation in chronic paranasal sinus disease. J Allergy Clin Immunol 2008;121:1435-1441.

31. Ito T, Hanabuchi S, Wang YH, Park WR, Arima K, Bover L, Qin FX, Gilliet M, Liu YJ. Two functional subsets of FOXP3+ regulatory $\mathrm{T}$ cells in human thymus and periphery. Immunity 2008;28:870-880.

32. Liao SC, Cheng YC, Wang YC, Wang CW, Yang SM, Yu CK et al. IL-19 induced Th2 cytokines and was up-regulated in asthma patients. J Immunol 2004;173:6712-6718.

33. Gallagher G, Eskdale J, Jordan W, Peat J, Campbell J, Boniotto $\mathrm{M}$ et al. Human interleukin-19 and its receptor: a potential role in the induction of Th2 responses. Int Immunopharmacol 2004;4:615-626.

34. Gallagher G. Interleukin-19: multiple roles in immune regulation and disease. Cytokine Growth Factor Rev 2010;21:345-352.

35. Zhang N, Van Zele T, Perez-Novo C, Van Bruaene N, Holtappels G, DeRuyck N, Van Cauwenberge P, Bachert C. Different types of $\mathrm{T}$ effector cells orchestrate mucosal inflammation in chronic sinus disease. $J$ Allergy Clin Immunol 2008;122:961-968.

36. Sa SM, Valdez PA, Wu J, Jung K, Zhong F, Hall L, Kasman I, Winer J, Modrusan Z,
Danilenko DM, Ouyang W. The effects of IL-20 subfamily cytokines on reconstituted human epidermis suggest potential roles in cutaneous innate defense and pathogenic adaptive immunity in psoriasis. $J$ Immunol 2007; 178:2229-2240.

37. Pawankar R, Nonaka M. Inflammatory mechanisms and remodeling in chronic rhinosinusitis and nasal polyps. Curr Allergy Asthma Rep 2007;7:202-208.

38. Lee HS, Myers A, Kim J. VEGF drives autocrine epithelial cell proliferation and survival in chronic rhinosinusitis with nasal polyposis. Am J Respir Crit Care Med 2009;180:1056-1067.

39. Dumoutier L, Leemans C, Lejeune D, Kotenko SV, Renauld JC. Cutting edge: STAT activation by IL-19, IL-20 and mda-7 through IL-20 receptor complexes of two types. J Immunol 2001;167:3545-3549.

40. Parrish-Novak J, Xu W, Brender T, Yao L, Jones C, West J, Brandt C, Jelinek L, Madden K, McKernan PA, Foster DC, Jaspers S, Chandrasekher YA. Interleukins 19, 20, and 24 signal through two distinct receptor complexes. Differences in receptor-ligand interactions mediate unique biological functions. J Biol Chem 2002;277:47517-47523.

41. Mrówka-Kata K, Namysowski G, Steplewska K, Gabriel A, Wysocka A. Immunohistochemical assessment of molecule Ki67 in nasal polyps tissue. Otolaryngol Pol 2007;61:958-961. 